\title{
Lightning related human risks.
}

\author{
Chandima Gomes* \\ Centre for Electromagnetic and Lightning Protection Research, Universiti Putra, Malaysia
}

\begin{abstract}
This paper provides a comprehensive account of lightning related hazards to human beings both at general locations and at work. The injury mechanisms are analyzed from both engineering and medical perspectives with the view of determining the factors to be considered in risk assessment for minimizing adverse impacts of lightning from both direct and indirect effects. The paper provides practical approaches in evaluating the degree of risk of lightning related injury to humans at nearly any given location. The paper highlights many dependent and independent parameters in determining safety assessment schemes against lightning-related human hazard. It also emphasizes the need for development of human safety guidelines in addition to established lightning protection standards that focus on property and services. While most risk index parameters are valid globally, in some cases, there may be special regional or local factors that should be considered.
\end{abstract}

Keywords: Lightning, lightning safety guidelines, step potential, direct strike, side flash, injury prevention.

Accepted on June 07, 2017

\section{Introduction}

Whereas extreme but infrequent events such as volcanic eruptions, tsunamis, hurricanes, cyclones, and earthquakes can take hundreds or thousands of lives and cause massive property destruction, lightning causes personal injury, death and economic loss at multiple places around the globe every day of the year. One paper estimated as many as 240,000 lightning casualties occur globally every year with at least $10 \%$ of those being fatally injured [1]. The reason that people are not more aware of its danger worldwide is that lightning incidents most commonly involve individuals or small groups of people, affect relatively tiny geographic areas, and may be in areas so remote that news coverage and reports to the authorities may be unlikely unless there is something unusual about an individual event. For example, in Uganda, nearly 100 people were killed and over 500 people were injured due to lightning in the year 2011 [2], but only one incident involving 18 children and their teacher reached readers outside of the region until the research paper was published in 2012. Later, it was revealed that the teacher had survived despite being severely affected by the strike. Another incident was the death of 11 football players in a provincial football match in Congo (Central Africa) in 1998. Frequently, there are deaths of 5-10 people per strike reported in Sri Lanka, Pakistan, India and Bangladesh and other tropical areas during the last decade [3].

Lightning casualties in the recent years have been reported by Mary and Gomes [2,4] in Uganda, Foster et al. in Zambia, Yi et al. and Zhang et al. in China [5], Cardoso et al., Cruz et al. and Navarette-Aldana et al. in Colombia and summarized in Holle [6-9]. Several of these studies were done specifically to document lightning risks to government officials in these countries to encourage injury prevention campaigns.

Even when people become aware of injuries and outages, they may not know or believe that there are ways to avoid the danger, be able to take lifesaving action or be able to afford lightning protection systems, particularly in less developed countries [10]. Even in more developed countries, with the most sophisticated lightning warning systems, lightning usually cannot be predicted beyond a few minutes in advance, although forecasts of thunderstorms that may contain dangerous lightning can sometimes be made hours to days in advance.

In addition to human deaths and often disabling injuries, property damage from lightning may involve losses varying from livestock deaths to significant expense from equipment downtime as well as destruction of dwellings and other buildings. A direct lightning strike may ignite fires, trigger explosions, cause structural fires, detachment or fragmentation of materials that either fall to injure those below or actually act as shrapnel [11-14], cause utility outages, and other economic losses. Indirectly, lightning current can permanently or temporarily damage electrical, electronic and communication equipment by entering a building through plumbing and service lines such as power, communication, and cable TV. In addition to hardware failure, these can cause significant data loss and operational downtime. The unanticipated equipment failures may have indirect effects on human casualties, especially if the damaged equipment and devices are used for vital medical applications, life support, food storage, and other essential operations.

When lightning affects a human being, injuries may range from simple tingling and muscle aches to cardiac arrest, brain injury, nervous system damage and death. While few in developed countries suffer from serious burns, the same may not be true in developing countries where keraunoparalysis, temporary paralysis from lightning lasting minutes to a few hours, may prevent even healthy individuals from escaping homes or work places where dry thatched roofs (Figure 1) have been ignited $[15,16]$. 


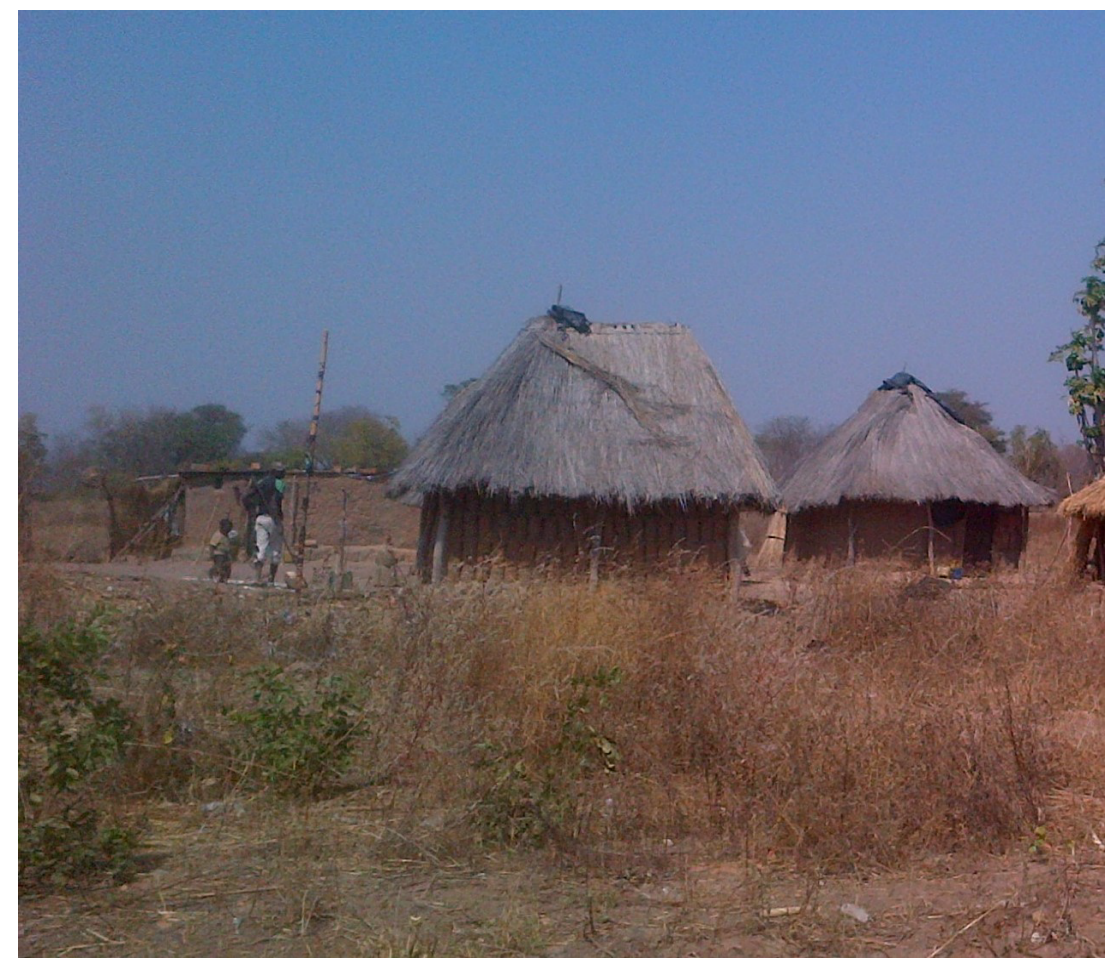

Figure1. Typical housing and work structures in developing countries involve mudbrick walls with a combination of flammable thatch and ungrounded metal roofs, often held down by stones. (courtesy Mary Ann Cooper).

Even in developed countries, lightning deaths are much more likely to be reported than lesser injuries. The 'rule of thumb' developed from several studies [17] is that about $10 \%$ of those injured by lightning die, leaving $90 \%$ as survivors who may have life-long disabilities including brain injury and chronic pain from nerve damage. Many will learn to accommodate for the injuries in time, but many will need to retrain or take lesser employment if they are able to return to employment at all. It is unknown if this $10 \%$ death / $90 \%$ survival split applies in developing countries.

Comprehensive accounts on region-wide lightning deaths and injuries have been given in Holle $[18,19,9]$, Cooray et al. and Gomes and Kadir [20]. These studies show the rate of lightning victims in the tropics is distinctly higher than that in the colder countries. This may be due to higher lightning density in tropical and subtropical countries (thunder days per year have a direct correlation to lightning density), population density, urban-rural ratio, labor-intensive agriculture and fishing, more open air structures and methods of transportation, construction practices, less availability of structures with 'Faraday Cage' effects, literacy rate, poverty, and probably other factors. The GomesKadir equation [21] can be used to make a rough estimation of annual lightning deaths and injuries in a given region. It also provides qualitative information on how the death rates will change due to various socioeconomic factors, apart from the geographic location.

Numerous studies have shown a trend for the majority of lightning victims in developing countries to be in labor intensive rural areas where many people are exposed as they work outdoors $[3,4,18,19,22]$. The first three studies show that victims belong to less educated social classes, so that dissemination of lightning protection and safety measures to all social levels is required to minimize injuries and deaths [2426]. Lightning deaths and distribution may be very different in developed countries where urbanization of the population and industrialization of farming has occurred, resulting in fewer people being involved in farming. As countries become more developed, injury patterns may shift to involve more people in outdoor construction and recreational activities just as it has in industrialized countries.

During the first decade of this century, noteworthy efforts have been taken by lightning safety educators to promote the safety guidelines in the developing world [21,22]. However, the small number of educators involved and the massive number of people in many developing countries with little access to educational programs or media has made lightning injury prevention knowledge dissemination an uphill task and may be a key reason for the remaining high number of lightning deaths and injuries in these countries despite the safety promotions that have been launched there $[27,28]$.

The purpose of this paper is to analyze the factors that influence the risk of lightning related injuries and propose to formulate safety mechanisms to minimize the risk of injury from direct strikes, side flashes or a nearby strikes.

\section{Existing Safety Guidelines}

The earliest lightning safety recommendations were often based on untested myths, superstitions, religious beliefs and other folklore. Many were at odds with one another $[29,30]$. One of the earliest international safety guides to be proposed and based on scientific data was by Ishikawa, Kitagawa and associates [31-34]. 
In 1998, an ad hoc Lightning Safety Group met at the American Meteorological Society. It included recognized lightning experts from many fields including meteorology, engineering, research, academics, medicine, physics, insurance, sports and the lightning protection industry. Most had been doing lightning safety briefings, media interviews, and publications individually, and many were professional colleagues. Because of new research on lightning strike distances and a desire to be consistent in messages, especially to the media, the individuals believed it was important to meet to write a consensus statement of recommendations on lightning risk, safety and injury prevention $[35,36]$. Before publication, the proposed guidelines were shared for review and comment with many respected lightning colleagues from around the world who were unable to attend the meeting personally $[18,19,26]$.

The recommendations formulated at this meeting included safety for individuals, for small groups with short evacuation time, and for large groups with longer evacuation times such as sports stadia or rock concert venues. They also included how to formulate a lightning safety action plan and the ' $30 / 30$ rule'. Recommendations noted that the only safer places for someone to go when lightning threatened was into a substantial building (containing indoor plumbing, wiring and framing in the walls) or a fully enclosed metal vehicle. The Lightning Safety Guidelines (LSG) were published as widely as possible in the respected journals of the participants [37].

Position statements incorporating LSG were developed by the National Athletic Trainers Association and the American Meteorological Society [38,39]. These guidelines were the basis for the original Lightning Safety Awareness Week [40-43]. Over the years, changes and updates based on research and 'best practice' have been incorporated into the information available on the Lightning Safety website (www.lightningsafety.noaa. gov) which also has teaching resources and media tools. It should be noted that these guidelines apply best to developed countries.

The context of the materials given in many USA based websites focuses on lightning safety issues related to the life style of USA public: ready accessibility to weather sites (electronic and audio visual media), fast dissemination of risk awareness through modern communication modes, and ready availability of sturdy structures and metal vehicles. Additionally, the guidelines also discuss the safety concerns related to a variety of activities common in the American day-to-day life: indoor and outdoor swimming pools, leisure and adventure camping, golfing and other sports/recreational activities.

In the last nine years, four symposia on lightning have been organized by patronage of Non-Aligned Movement Science and Technology Centre in four countries: Sri Lanka in 2007, Nepal in 2011, Uganda in 2013 and Zambia in 2015. At each conference, issues related to lightning safety in developing countries were discussed and recommendations documented as individual research papers $[44,45]$ and resolutions (Colombo Declaration, Kathmandu Resolution, Entebbe Resolution, and Resolution for Declaration of an International Lightning Safety Day) focused on developing policies at various administrative levels.

\section{Information and Risk Analysis}

\section{Lightning characteristics}

Lightning is an electrical process that neutralizes atmospheric electric charge. While convective thunderstorms are the main source of lightning in many parts of the world, it can also be generated in other types of clouds, as well as in sand, hail and snow storms, ash masses ejected in volcanic eruptions, and the dust-mushroom created by nuclear explosions. However, due to the scarcity of other types and the extremely low probability of such types affecting human beings, this paper addresses only lightning from thunderstorms.

While the majority of lightning is usually within clouds, lightning can always extend to the ground, harming people and property. It initiates inside a cloud in the form of a channel of electric charge. This channel is called a "stepped leader" due to its stepping nature in the propagation towards ground. When the stepped leader, which usually brings negative charge to ground, is about 50-100 meters above ground, oppositely charged upward streamers, called answering or upward leaders, are spontaneously generated from all nearby objects including hills, trees, rocks, towers, buildings, service lines, human beings, and animals. Usually, one or more of the answering leaders will meet the stepped leader and a large current flow will occur through the object which sent the particular answering leader. That object is then treated as "lightning struck". In a single strike, current pulses may flow a number of times through the object struck. The current pulse that flows into ground results in a potential gradient wave that propagates along the channel to cloud, taking earth potential with it. This potential gradient wave is termed the "return stroke". The first current pulse that flows is termed the "first return stroke current", and the successors are termed "subsequent return stroke currents".

Out of the total lightning observed in tropics, about $60 \%$ occurs between clouds or inside a single cloud [20]. These are termed cloud or intra-cloud flashes and have insignificant effects on living beings and equipment at ground level. Out of cloudto-ground flashes, the ones that are dangerous to people and property, about $5 \%$ of tropical strikes bring positive charge to ground [26]. In temperate regions, this percentage may vary from $15-60 \%$ [46-48].

The lightning current is a short term transient which has a double exponential form and lasts about $100 \mu \mathrm{s}$. The rise time of the pulse in the first return stroke current may be a few microseconds, while that of subsequent strokes may be in the sub-microsecond range. On average, the peak of the lightning current impulse is about 30,000 amperes for negative first strokes and half of that for subsequent strokes. In positive strokes, on the other hand, the peak impulse current reaches 250,000 amperes on average and has longer rise times and duration. Positive lightning is most often single stroked and much more unpredictable than negative lightning [46-49,50].

The microsecond scale current impulse is sometimes followed by a slow varying component that may last for hundredths of milliseconds. These current components, which have amplitudes in the order of a few hundred to a few thousand amperes, are termed "continuing currents". The continuing current is a 
prominent feature in positive lightning although it has been observed in negative lightning as well [51-54]. From research done in several countries, continuing current plays a significant role in igniting forest fires $[55,56]$.

The passage of lightning current may heat the channel to as much as 30,000-40,000 degrees Kelvin [56], many times the surface temperature of the sun, about 6000 degrees Kelvin. The rapid increment in temperature in the lightning channel leads to an explosive expansion of air. This rapid expansion generates a cylindrically symmetric shock wave that travels tens of meters to decay as a burst of sound waves, which we call "thunder". Due to the lower speed of sound waves in air (about $330 \mathrm{~m} / \mathrm{s})$ compared with the speed of light $\left(3 \times 10^{8} \mathrm{~m} / \mathrm{s}\right)$, the light of lightning reaches an observer before the sound of thunder does. As a rule of thumb, the time in seconds between the observation of the light and the thunder is approximately three times the distance in kilometers or five times in miles to the lightning strike from the point of observation. This is the basis of the 'Flash to Bang' method of estimating the distance someone is from lightning [57]. This method is no longer commonly used in developed countries due to the difficulty of correctly matching thunder to the correct lightning flash and to errors in remembering the calculation, which frequently leads to underestimation of danger by a factor of three or five.

The presence of static and dynamic electric charge in the lightning channel generates electromagnetic fields that may be detected as far as $100 \mathrm{~km}$ from the lightning channel. The field is very strong at close range, but decays rapidly (approximately following inverse square law) with distance. The time profile of these lightning generated fields varies depending on the distance from the point of strike. Factors such as lightning type, profile of lightning current at the channel base, ground/ seawater conductivity, channel tortuosity, channel branches and other factors can affect the exact nature of the electric and magnetic fields observed at a particular location. These fields may also induce significantly high voltage pulses in electric and telephone service lines in the vicinity or enter structures through these lines, damaging equipment and people [58].

An instantaneous potential gradient is induced during the passage of lightning current along and around the lightning struck object. The magnitude of this potential difference depends on the impedance (mainly inductance and resistance) between any two points of concern along the object. The inductive effect basically depends on the number of paths available for the lightning current to flow. Lightning current passing through a highly resistive material, such as wood, bricks or cement, can generate a very high potential difference. For lightning flashes with even moderate peak currents, this potential difference may reach values exceeding millions of volts, if the two points of concern are far apart. A large potential gradient can lead to side flashes as the lightning takes one or several aerial routes to reach the earth masses. Such side flash arcs are extremely dangerous as they generate an enormous amount of heat that may cause fires and explosions. Side flashes may be as hazardous as direct strikes to human beings.

In contrast, when the lightning current travels along several parallel paths through good conductors such as a copper, aluminum, and iron, the potential difference between two points separated by a similar distance will be much less. Modern structural lightning protection systems depend on the physical concept of well-conducting parallel paths giving rise to very low potential gradients and good heat dissipation as they divert the current around more resistive and fire or injury prone objects in its path.

Another component of modern lightning protection systems is the neutralization of the inrush of charge as it enters the earth. This may require the installation of multiple, interconnected grounding electrodes (metal rods, tapes, and other components) across a sizable area around the protected object. In the absence of a well distributed, man-made grounding system with low earth resistance, large potential drops may develop radially between the point of strike (the point at which lightning current enters the earth) and the peripherals.

With respect to a distant point, the potential at the point where the lightning current enters the ground may reach values in the order of several tens to hundreds of kilovolts. The decrement of potential radially away from the current injection is termed the "earth potential gradient" (EPG). The EPG can be very large where the earth resistance of the soil in the area has a large value. The EPG may lead to surface currents that flow in many directions from the point of current injection. Experiments with artificial or triggered lightning have generated surface arcing (charge neutralization taking place on the surface of the ground in the form of electric sparks) that extend to more than 10-20 $\mathrm{m}$. Even in the absence of sparking, the surface currents that flow as a result of high EPG may damage equipment and living beings on their paths. As a result, EPG is an important topic in any study on lightning safety. Other names for EPG are ground current, earth potential rise, step potential, voltage gradient.

\section{Mechanisms of injury}

This paper is limited to the effect of lightning on living beings. The impacts of lightning strikes to buildings and lightning currents to equipment are addressed only within the context of the effects of such events on living beings. A detailed study on structural protection can be found in IEC 62035:1-3 and NFPA 780. The details of equipment protection are given in IEC 62035:4, IEEE C62.41, and Gomes.

\section{Direct strikes}

If a person is the object which sends the answering leader that successfully meets or 'attaches' to the downward stepped leader, he will be the terminus of a direct strike. The entire lightning current may take external or internal paths (sometimes both) depending on the person's internal body impedance and impedance of the skin and clothing. Usually, lightning pulses through the person for a very brief period before 'flashing over' the outside of the person.

The probability of a person sending an answering leader to intercept the stepped leader is related to the height and isolation of the person in a given landscape. The influence of his bodywear (especially the footwear), metallic components, nonionizing radiation emitters such as mobile phones, shape of armaments, and other factors on the inception of answering 
leader are yet to be studied in a controlled manner. A notable point in this regard is the information available in mass media on the victims of direct strikes using mobile phones. The common belief among the scientific community is that there cannot be any relation between the emission of low intensity nonionizing radiation and the inception of an answering leader. The overwhelming number of such incidents reported in the media should not be overlooked outright, although it is likely more related to the ubiquitous use of cell phones and their potential for distraction than to any electromagnetic effect. Further, most reports are written or edited by media professionals with limited scientific knowledge on the matter and no direct knowledge of the incident they are writing about.

A direct strike may attach to the body of an erect victim at the head or shoulders (Chandima Gomes unpublished data; based on information from Malaysia, Sri Lanka and Bangladesh). Clinical observation has shown many cases of lightning victims of direct strikes have no visible sign of entry or leaving points of lightning current (Mary Ann Cooper, MD, unpublished data; personal communication with Chris Andrews, MD, $\mathrm{PhD}$ ), unlike high voltage electrical injuries which commonly have significant burns at ground and source points. Similar cases have been reported from Bangladesh as well. Hence, in forensic investigations, it is of prime importance that lightning not be excluded as a cause of death simply due to the absence of visible injury such as burns, red/purple brown/black patches, holes and similar skin changes [14].

Estimates of fatalities due to direct strike in developed countries are as low as 3-5\% of cases [43]. However, in developing countries, the risk of direct strikes may be different. The isokeraunic level of the region, topography of the home and work place, the victim's occupation and behavior, socioeconomic status, literacy level and other factors may influence the exposure and level of risk of injury [20]. For an example, in Malaysia, a majority of direct strike victims are Indonesian laborers, who may opt to work in open construction sites despite approaching thunderstorms as they cannot afford to lose a day's wage.

Due to the same reason mentioned above, the popularly practiced lightning safety guideline against direct strikes in USA and many other developed countries, the 30/30 rule is hardly applicable in many underprivileged communities in developing countries. The rule states that if it takes less than $30 \mathrm{~s}$ to hear thunder after seeing the optical output of a flash, lightning is near enough to pose a threat; after hearing the last thunder, a period of 30 minutes should be spent indoors before resuming outdoor activities. The rule is based on the assumption that if a ground flash occurs more than $10 \mathrm{~km}$ away, the risk of getting the next flash at the point of observation is very low and if there is no flash within 30 minutes the storm is either disintegrated or beyond the peripherals of posing a threat. The experience of authors in South Asia and Africa reveals that people who work for daily wage may be reluctant to give up their activities for such period. On the other hand, even if they are ready to follow the rule, they may not find a sturdy building for seeking shelter within a reachable distance. Such observation demands reformulating a new guideline or developing a feasible mechanism to minimize the risk of lightning related injury, which suits the socio-economic structure of developing countries.

\section{Side flash}

Previously, it may be prudent to generalize recommendations as 'Stay away from all taller objects to avoid side flashes'.

Cooper et al. [43] estimated lightning fatalities due to side flash to be approximately $20-30 \%$ of fatalities in developed. In a side flash, the entire lightning current or a portion of the lightning current may pass through and/or around the human body due to the transfer of energy from a lightning struck object to someone in the proximity. This is frequently seen when a person seeks shelter underneath a tree and is injured as a side flash jumps from the tree when it is hit by lightning. The amount of energy delivered to a person will be affected by how much goes through other pathways on the way to ground and is roughly inversely proportional to the resistance of the various pathways.

The lightning current that enters a human or animal body may not be different whether it is a direct strike or a side flash, as lightning is a current generator. The profile or amplitude of a lightning current may not be altered by the impedance of an object at ground level through which it flows in its passage to earth. However, while in the case of direct strikes, the head and the shoulders are the prime targets of attachment in someone who is standing, a side flash may contact any part of the body.

It should be noted that the side flashing point need not be a metal part as there are large number of cases where the arcing has happened from the branches or trunk of a tree. Many reports published in the last century (Golde; IEC 61024-1; NFPA 780) specify a minimum separation of $2 \mathrm{~m}$ for the distance between a possible side flashing point and the human body part closest to that point. However, because the arcing distance depends on many parameters such as the medium between the two points connected by the arc, the number of paths available to the lightning current to flow and their path lengths, the specification of fixed value of separation has been removed in the recent standards (IEC 62305, 2010). It may be prudent to generalize recommendations to stay away from taller objects.

A formula can be proposed for the calculation as given in Eq. 1. A possible case is given in Figure 2 (refer IEC 62305 for complete details).

$$
S=k_{i} \frac{k_{c}}{k_{m}}
$$

where

\section{$k_{i}$ depends on the selected Level of Protection}

$k$ depends on the lightning current flowing on the downconductors

\section{$k_{m}$ depends on the electrical insulation material}

$l$ is the length, in meters, along the air-termination or the downconductor (from the point where the separation distance is to be considered) to the nearest equipotential bonding point. In the case depicted in Figure 2, the ground surface can be treated as the equipotential surface.

Consider a case where Level I protection is assigned with only one current path (down conductor) which is provided by the conductor in Figure 2. If we adopt the following values for the parameters as per IEC 62305-3. 


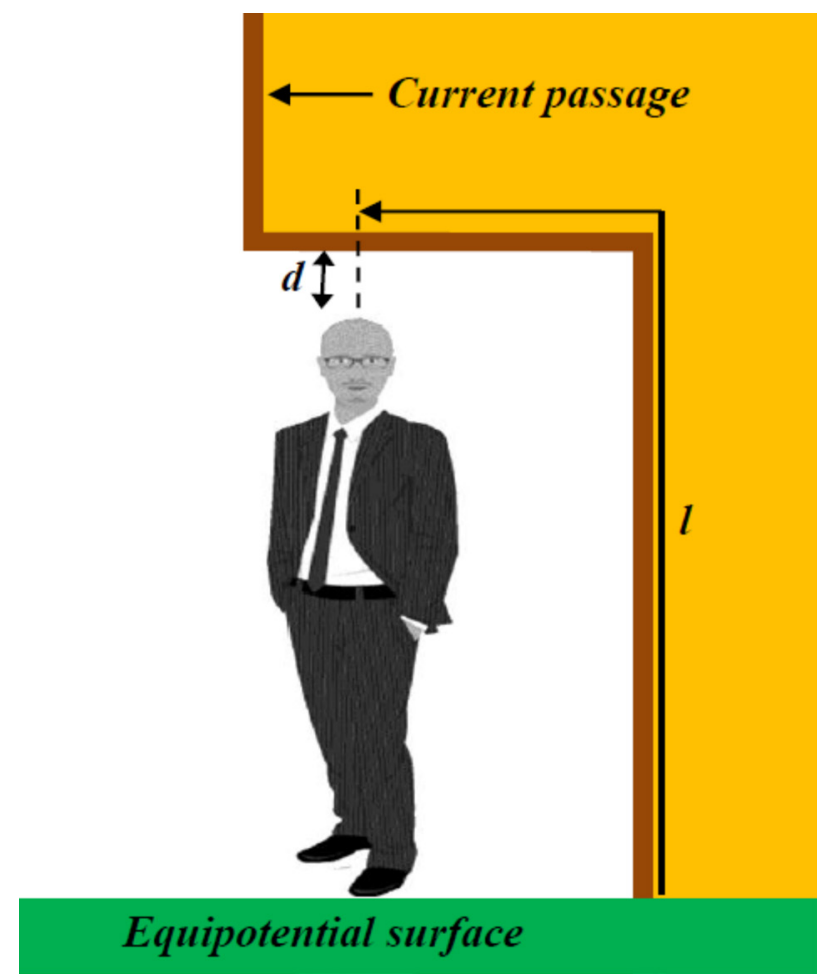

Figure 2. The separation distance to be kept between the down conductor and a human body. The distance $d$ should be greater than the minimum separation s obtained from the calculations recommended in IEC 62305-3 (2010). Note that it is more appropriate to consider the height of the human being with his hand raised.

$k_{i}=0.08$ (Level of Protection: I)

$k_{c}=1$ (number of down conductors: 1 )

$k_{m}=1$ (insulation material that separate the two systems: air)

$l=2.0 \mathrm{~m}$

Eq. 1 gives $S=0.16 \mathrm{~m}(16 \mathrm{~cm})$, IEC $62305-3$ clearly states that the minimum number of down conductors to a given installation is two. Hence for the given situation the minimum separation reduces to $8 \mathrm{~cm}$.

We have serious concerns regarding the application of Eq. 1 given in IEC 62305-3 as per our observations in a number of countries. There are over 20 incidents observed in South Asian regions and Malaysia where the arcing distance has been 4-5 times greater than the values obtained from the above calculations considering even Level I protection (highest level which provides the greatest separation). Following is one such situation recorded in Malaysia.

CASE 1: A person in his late 20 s was killed by a lightning strike while he was standing in the living room of his home. The metal roofed house, built on wooden supports and wooden covering, was situated in a large oil palm plantation in Port Dickson, a coastal city. The youth was standing in the living room where he was struck by lightning while other family members seated on a couch a few meters away witnessed the incident. With the information gathered from the site and records of eye witness, it was very clear that the victim had been struck by a side flash to the head emanating from the metal roof. Calculations by Eq. 1 show that even at Level I protection with one down conductor (situation that demands the maximum separation distance), the safety distance is below $50 \mathrm{~cm}$. However, the distance from the possible position of the head of the victim and the nearest metal extension of the roof was approximately 1.5-2 m.

There are two possible reasons for the failure in predication by Eq. 1 .

a. Although we consider one down conductor in the calculation (least number) there may be no proper down conductor in this situation.

b. The equation does not consider the material or shape/ dimensions of the arcing points.

In many cases of zero down conductors or improper down conductors, as in the above case from Port Dickson, Malaysia, the only option left for Eq. 1 is to take the number of down conductors as one (the minimum number). Development of a model to calculate the minimum separation, considering the nature of available paths for lightning current and the properties of arcing points, will be highly complex due to the large number of dependent and independent variables. Even after developing such formulas, application in many situations will be too complicated due to the unavailability of site parameters. This is a situation that demands a new way of thinking that can produce a model which may calculate separation distance with acceptable level of accuracy and be mathematically simple at the same time. Until such formula is developed it is strongly advised that Eq. 1 be used with caution in real life-situations. As noted countries. It is not known what proportion of injuries in developing countries may be due to side flash (also termed side splash). 


\section{Step potential}

A partial current may pass through the body due to the injection of current into earth from a nearby lightning strike if two parts of the body in contact with ground align in the direction of the potential gradient which develops. For an example if the feet of a person who is standing are aligned in the direction of increasing potential, the potential difference between the feet can cause a current to flow through the body between the two feet.

The magnitude and duration of the current depends on the potential difference and body resistance between the feet and the contact resistance between the flesh of the feet and the ground. Any material such as the sole of a shoe, socks or roughness of the ground will increase the contact resistance and, in turn, reduce the current through the body, but not necessarily by a clinically significant level. Although wearing rubber soled shoes or footwear made of any other insulation material may potentially be advisable during thunderstorms, the amount of safety that it provides is minimal. In addition, this would have no effect in reducing the probability of being the target of direct strike or side flash.

The potential difference between the feet depends on the lightning current injected into the ground at the point of strike, proximity to the point of strike, soil resistivity of the ground and the separation of the body parts that is in contact with the ground. The first three points significantly contribute to the large number of human casualties reported in many South Asian countries, popularly known as "lightning knocked off" cases, in proximity to communication and broadcasting towers (personal observations of authors in Sri Lanka, India and Bangladesh; Chandimal and Gomes). Many towers are built on isolated rocks and are the tallest protrusion in the vicinity, resulting in them frequently becoming a striking point. Once lightning attaches, the total current is injected into a small footprint of the tower with massive current density at ground entrance point due to the extremely high soil resistance on the rocky surface. Research done on communication towers and triggered lightning reveals that, in the event of current injection into ground within a small region, dangerous surface potential gradients may arise as far as $150 \mathrm{~m}$ from the base of the structure $[47,48]$. These potential gradients may even create visible surface arcing of lengths up to tens of meters [59]. There are several "knock-off" cases reported in Sri Lanka and Bangladesh for victims standing as far as $100-150 \mathrm{~m}$ from the tower.

Persons lying down asleep during thunderstorms are at particular risk of serious injury due to step potential effects as the greater the separation between the body parts, the higher the potential difference that the person is subjected to. The potential gradient, which appears across the entire body, will drive the current through vital organs of the body of a person who is lying down. This also explains why four-legged animals are more susceptible to injury and death from step potentials than two legged human beings.

Cooper et al. [43] estimated lightning fatalities due to step potential to be approximately $40-50 \%$ of fatalities in developed countries. It is not known what proportion of injuries in developing countries may be due to step potential.

\section{Touch potential}

A partial current may pass through a person if part of their body comes in contact with part of a lightning struck object while another, usually lower, body part remains in contact with ground, such as would happen if a person were touching a flag pole struck by lightning with their hand while standing on ground. Accidents due to touch potential may also arise when a person using a hard wired telephone, plumbing or repairing electrical systems connected to the power line is in contact with any metallic part which is exposed to the path of lightning current (e.g. metallic railing from the roof top which is connected to the lightning protection system at the roof top level).

Cooper et al. [43] estimated lightning fatalities due to touch potential to be approximately $15-20 \%$ of fatalities in developed countries. It is not known what proportion of injuries in developing countries may be due to touch potential.

The current through the body due to touch potential depends on the resistance along the original path and the total resistance between the point of touch and the closest equipotential bonding. If a person touches a bare down conductor, which has been erroneously laid in the interior wall and is in contact with the steel reinforcement mesh of the floor, the closest equipotential bonding is the metal steel mesh. The resistance along the original path is the resistance of the copper tape between the point of touch and the steel mesh (Ro). The total resistance $\left(\mathrm{R}_{\mathrm{T}}\right)$ between the point of touch and the equipotential bonding across the body is the sum of contact resistance at the hand $\left(\mathrm{R}_{\mathrm{CH}}\right)$, body resistance $\left(R_{B}\right)$, contact resistance at the foot $\left(R_{C F}\right)$, and the resistance between the surface and the steel mesh $\left(\mathrm{R}_{\mathrm{Con}}\right)$. This relation is depicted in Eq. 2.

$\mathrm{R}_{\mathrm{T}}=\mathrm{R}_{\mathrm{CH}}+\mathrm{R}_{\mathrm{B}}+\mathrm{R}_{\mathrm{CF}}+\mathrm{R}_{\text {Con }}$

The greater the value of $R_{T}$ with respect to Ro (i.e. $R_{T}>>R_{o}$ ), the smaller the current through the body of the victim. $\mathrm{R}_{\mathrm{CH}}$ can be increased by covering the down conductor with an insulation sleeve. The IEC 62305-3 recommends that parts of the down conductor within the reach of a person be covered with insulation material. $\mathrm{R}_{\mathrm{CF}}$ can be increased by wearing shoes and by having a layer of insulation over the concrete such as ceramic tiles or PVC carpets. It is specifically recommended to cover the area of radius about $1 \mathrm{~m}$ around the point where down conductor enters ground with a $10 \mathrm{~cm}$ layer of gravel in addition to the sleeving of the down conductor up to $2 \mathrm{~m}$ height above ground level.

In typical cases, the current through the body will be much smaller than in the case of step potential, as, most often, $R_{o}$ is extremely small. However, in contrast to most cases of step potential, the current resulting from touch potential may flow through many vital organs causing karaunoparalysis, cardiac arrhythmias, brain and nervous system injury. In rare cases, lethal secondary injuries may occur if the person is at the edge of a height or at risk of drowning from being in a small boat or near water.

\section{Upward leaders}

In the presence of the downward step leader, many nearby objects in contact with ground may send answering leaders that carry 
opposite charge upwards. The risk of completion between these answering leaders ends when one or more of them connects with the stepped leader. Subsequently, the unsuccessful answering leaders disappear either due to dispersion of charge to air or reflow of charge to ground. During this answering leader phase, currents with relatively low amplitudes flow along the body of the objects that send such leaders. However, the duration of these leader currents may reach seconds in contrast to the durations of lightning currents which are in microseconds to milliseconds. Such long duration currents with almost uniform amplitudes may cause damage to vital organs or cardiac arrhythmias. This phenomenon is popularly known as the "Fifth Mechanism of Lightning Injury". Cooper et al. [43] estimated lightning fatalities from upward leaders to be approximately 10$15 \%$ of fatalities in developed countries. It is not known what proportion of injuries in developing countries may be due to upward leaders.

\section{Proximity to the strike and barotrauma}

The concussive shock wave generated by the lightning current channel due to sudden expansion of air may damage the skin, vital organs or ear drums when the victim is close to the point of strike. One researcher has labeled this as the sixth mechanism of lightning injury and baptized the effect as electromagnetic blasting [14,52]. The researchers of the above work suggest classifying the effect as a primary lightning injury mechanism. Other lightning experts disagree with this, pointing out that the first five mechanisms are electrical in nature and that barotrauma or blunt trauma from being thrown as a result of muscle contraction can overlie any of the first five mechanisms, making them and their effects inseparable.

\section{Other mechanisms and medical effects}

A person struck by lightning does not retain or carry any current or residual charge, so there should be no delay in giving first aid and resuscitation. On average, $10-20 \%$ of strike victims die and up to $70 \%$ of survivors may suffer long term disabilities. These injuries are primarily neurological, with a wide range of symptoms, are usually permanent, and may be disabling. The passage of current inside and around the body may lead the person into ventricular fibrillation (chaotic, unsynchronized muscle operation of the heart), respiratory arrest (cessation of breathing), damage to vital organs such as brain, liver, kidneys, and, rarely, bleeding due to rupture of blood vessels. The person may also suffer from nervous system damage, keraunoparalysis and paresis (weakness), broken bones and loss of hearing or eyesight. Lightning injury can lead to permanent lifelong disabilities, most commonly brain injury similar to concussive injury, balance problems and chronic pain syndromes. A much more complete discussion of the medical effects can be found in Cooper et al. and of how they may differ in developing countries in Cooper.

The intense light emitted during the return stoke phase may cause vision impairment in both human beings and animals. Many other visual effects have been reported [41]. Some are temporary; others may be permanent. Detailed studies are required for the development of correlation between lightning current, proximity and effects on the vision. Quantitative investigation of the effects of X-ray and $\gamma$-ray emission by the lightning channel on a human body in the close vicinity may also be of interest.

There are several secondary effects when there is a person at proximity to the lightning flash such as falling from higher elevations due to momentary shock, falling of heavy materials from structures or trees (detached due to lightning strike) on the person, burns due to volatile materials in the surrounding area that catch fire, missiles or shrapnel due to splits and chipping off of struck objects or pavement, emission of toxic gases and ejection of fragments due to the blasting of exposable materials as well as psychological trauma due to the shock wave and destruction in the vicinity.

\section{Injury prevention tools}

The vast majority of lightning casualties can be avoided, at least in developed countries, through public education of individuals and of communities to adopt proper lightning safety and protection measures [28]. Many of these measures, such as standardized lightning protection systems for structures, lightning warning systems and ready access to medical facilities, are not that viable in many developing countries at present (especially in the rural areas). Many other safety guidelines could be easily, cheaply and readily implemented. Such measures are: training the public to follow simple safety procedures, giving basic medical attention to victims and implementing low cost protection schemes. Many materials that can be modified or customized for public education in other countries are available for use at www.lightningsafety.noaa.gov.

\section{Discussion}

The degree of risk of injury or death from lightning depends on many factors. The IEC 62305-2 (2010) provides a comprehensive risk assessment tool that can be used to develop a total lightning protection system aimed at reducing the risk of injury and damage for occupants of the protected structures. Unfortunately, these Standards do not yet specify safety guidelines for human beings independent of the protected structures. Furthermore, its complex nature and abstract approach makes it impractical for the general public.

The lack of consideration of various practical scenarios in different countries also makes Standards 62305-2 nonapplicable in many cases of human safety assessment. An investigation reported in Gomes and Kadir revealed that, out of 38 companies involved in lightning protection in several countries of South, South East and Middle East Asia, only three had the capability of conducting a risk assessment according to IEC $62305-2$. About $50 \%$ of the companies managed to carry out risk assessment according to the outdated British Standards BS 6651, which provide a simple calculation to decide whether a building requires lightning protection or not. Gomes and Kadir concluded that the level of present-day usage of standards in calculating lightning risk is significantly low.

If companies involved with lightning protection ignore IEC 62305-2, stating that the calculations are cumbersome (despite the availability of software), the public cannot expect a better response from the general engineering or risk indexing 
communities. Less complicated guidelines to estimate the degree of risk encountered by an individual or group of people from lightning are long overdue and badly needed.

Parameters that influence the risk of injury of human beings to lightning are listed and described below. Several parameters are relevant to both outdoor and indoor safety while a few are relevant to indoor safety alone.

\section{Ground flash density $\left(N_{g}\right)$ of the area}

Obviously, $\mathrm{N}_{\mathrm{g}}$ plays a big role in the lightning risk assessment. If the area of concern has high $\mathrm{N}_{\mathrm{g}}$, then the risk of lightning injury is usually also elevated for a given population density. However, most countries with very high lightning injury records, such as Bangladesh, Sri Lanka, Zambia, Nigeria, and Uganda, have no lightning detection systems to compute the ground flash density contours. There are many methods that have been used to measure ground flash density. A comprehensive discussion and comparison of available lightning detection systems has been given in Nag et al. [60].

\section{Thunder days $(T)$}

Thunder days, defined as the number of days on which thunder is heard by an appointed meteorological observer in a given area per year $\left(\mathrm{T}_{\mathrm{g}}\right)$, sometimes also called the isokeraunic level, is used by many countries as the input parameter for estimating $\mathrm{N}_{\mathrm{g}}$. Gomes and Kadir, list a number of errors introduced in the process of determining $\mathrm{T}_{\mathrm{g}}$. Further discrediting this method, there are no accurate ways of converting $\mathrm{T}_{\mathrm{g}}$ into $\mathrm{N}_{\mathrm{g}}$.

$\mathrm{T}_{\mathrm{g}}$ numbers are affected by many factors. A given day is taken as one thunder day, regardless of whether there is a single lightning or 100 lightning incidents. On the other hand, the hearing of thunder may be due to a cloud flash, but it is still counted as one thunder day. Since thunder is heard only up to about $15 \mathrm{~km}$, unless observers are placed in grid points of an imaginary mesh with segment widths of not more than 15 $\mathrm{km}$, the counts they supply cannot be obtained with accuracy. In most of the countries where the operation of meteorological departments has been checked, such placement of observers is seldom practiced so that $\mathrm{T}_{\mathrm{g}}$ data is questionable at best.

While there are several empirical formulae available for converting $\mathrm{T}_{\mathrm{g}}$ into estimates of $\mathrm{N}_{\mathrm{g}}$, none have been verified with universal sets of accurate lightning data to generalize their applications globally. Such drawbacks and limitation in data collection and manipulation makes the estimation of $\mathrm{N}_{\mathrm{g}}$ through $\mathrm{T}_{\mathrm{g}}$ highly erroneous, sometimes by even greater than $100 \%$. Such inaccuracy in $\mathrm{N}_{\mathrm{g}}$ may explain the observation of high lightning injury records in areas of relatively less lightning density (estimated via isokeraunic level) in Bangladesh, Pakistan and Sri Lanka [21].

The above information demands revisiting the determination of risk factor based on $\mathrm{N}_{\mathrm{g}}$. Unless the ground flash occurrence density in a given region can be directly determined by a ground mounted lightning detection system with a high level of accuracy, a factor of uncertainty should be introduced to the $\mathrm{N}_{\mathrm{g}}$ in calculating the final risk index of human injury.

\section{Topography of location}

In most of the literature, a high risk index has been assigned to elevated locations. While this would seem to be obvious, our investigations in Malaysia, Sri Lanka, Pakistan, Bangladesh and several African countries show that many areas are either unclassified or that more classification and topographic analysis needs to be done before an appropriate risk factor can be assigned for a given location.

Lightning accidents reported in Gomes and Kadir and observations in Uganda show that there are many victims on hill-slopes, rather than on hill-tops, at the time that they were injured, most with little or no vegetation. As reported in Gomes, several incidents of animal deaths due to lightning, including two cases involving over 800 animals killed in each case, occurred on hill slopes, many facing bodies of water.

Forty-eight lightning damaged buildings in Sri Lanka and Malaysia located within a short distance from water masses (lakes or large rivers) were identified. In $98 \%$ of the cases (47 buildings), the lightning attachment point faced the direction of water mass. In thirteen buildings, lightning struck more than once, and, in all cases, the locations of the strikes faced the water mass.

In Bangladesh, Uganda, Zambia and Sri Lanka, it has been observed that lightning accidents have taken place in flat lands with large spans of no or low vegetation growth. Two such prominent incidents took place in Sri Lanka in 2008 in the dry zone of the north central province where the isokeraunic levels are much lower than that in many areas of the wet zone. Within a span of few months, 8 soldiers (4 in each case) were killed and over 50 others were injured due to lightning. In both cases, the victims were grouped during the time of strike at locations which were flat and open with no land mass or objects of high elevation for a long distance.

The above observation shows that elevation of the location alone is not always a determining factor for the exposure to lightning. Instead, the topography and the environment such as vegetation, proximity to water mass, and other factors may play significant roles in determining the location of strike. In summary, one can conclude that an isolated object has a higher possibility of being struck by a direct lightning strike, whether the location is elevated or not.

\section{Effective safe distance for avoiding side flash}

Our investigations of lightning accidents in many developing countries show that side flash is the predominant mechanism of injury, with most of those reported being fatal and often occurring because people are attempting shelter inside insubstantial buildings. This could be because non-fatal incidents or those involving only one person are not newsworthy enough to be reported either by the media or to government authorities. The most probable outdoor scenario of side flashing from tall trees; whereas indoors, side flashing often occurs as arcing from a metal roof which has no or poor grounding (Figure 3).

As was discussed earlier, determining the effective safe distance for a given situation does not lend itself to an exact calculation. 
Based on theoretical calculations, Nourirad et al. showed that in determining the safety distance from an isolated uniform structure such as a wooden pole, even Eq. 5 could not provide accurate value as the distance of side flash depends on many factors that are not taken into account in formulation of this equation. These factors include the resistivity and height of the lightning struck object, soil resistivity, and lightning current waveform and amplitude. Prediction of potential side flashing becomes even more complex when the object is non-uniform and non-isolated.

However, based on our observations and experience, some general recommendations can be made to minimize side flash:

i. Under no circumstances, should one seek shelter under or close to a large tree during an ongoing or approaching thunderstorm.

ii. One should not seek shelter in a temporary hut or makeshift shelter during thunderstorms.

iii. For a permanent structure with metal roofing and wooden structure to be reasonably safer, it should be protected by minimum of two down conductors and an adequate grounding system. Low cost methods of doing this are described in Gomes et al but have yet to be validated by research. Once the down conductors are installed, the minimum separation should be calculated by applying Eq. 5. However, as per the shortfalls of Eq. 5 and the observations on arcing from the metal roofs, we would like to propose a minimum of $2 \mathrm{~m}$ separation (if the minimum separation obtained by Eq. 5 is less than 2 $\mathrm{m}$ ) between the roof and the highest-elevated body part. This is an impossibility in many homes and workplaces as they currently exist in many developing countries (Figures 1 and 3). iv. There is no need to specify a minimum separation between walls and the inhabitants in a sturdily built structure with lightning protection unless there is a down conductor in the proximity.

v. Until conclusive analysis is done, the public should be advised not to carry metallic items or to shed any metal parts of the body-wear during thunderstorm periods, especially when someone has no option but to seek shelter in unprotected structures. These maneuvers should never delay the more important action of seeking safer structures. Even if it is eventually found that there is no increased risk of lightning side flashes to these metal parts, burns are known to occur from metal that is in contact with a person when it is struck. Estimation of safer distances for keeping such metal parts in the vicinity of a potential lightning interception point should be done once suitable equations are formulated and accepted at the international level.

\section{Effective safe distance for avoiding step potential hazards}

In the event of a cloud to ground lightning flash, development of potential gradient radially away from the point of strike is unavoidable. It is essential to minimize the risk of injury from this whenever possible. The effective minimum safe distance to avoid hazardous step potentials depends on a number of parameters as described earlier. Based on that discussion, the following recommendations could be made.

i. The area span through which lightning current enters into ground determines the potential rise and potential gradient. Hence, those who live close to tall metallic towers, tall buildings and structures with a single down conductor should keep themselves at a considerably large distance from such possible lightning interceptors.

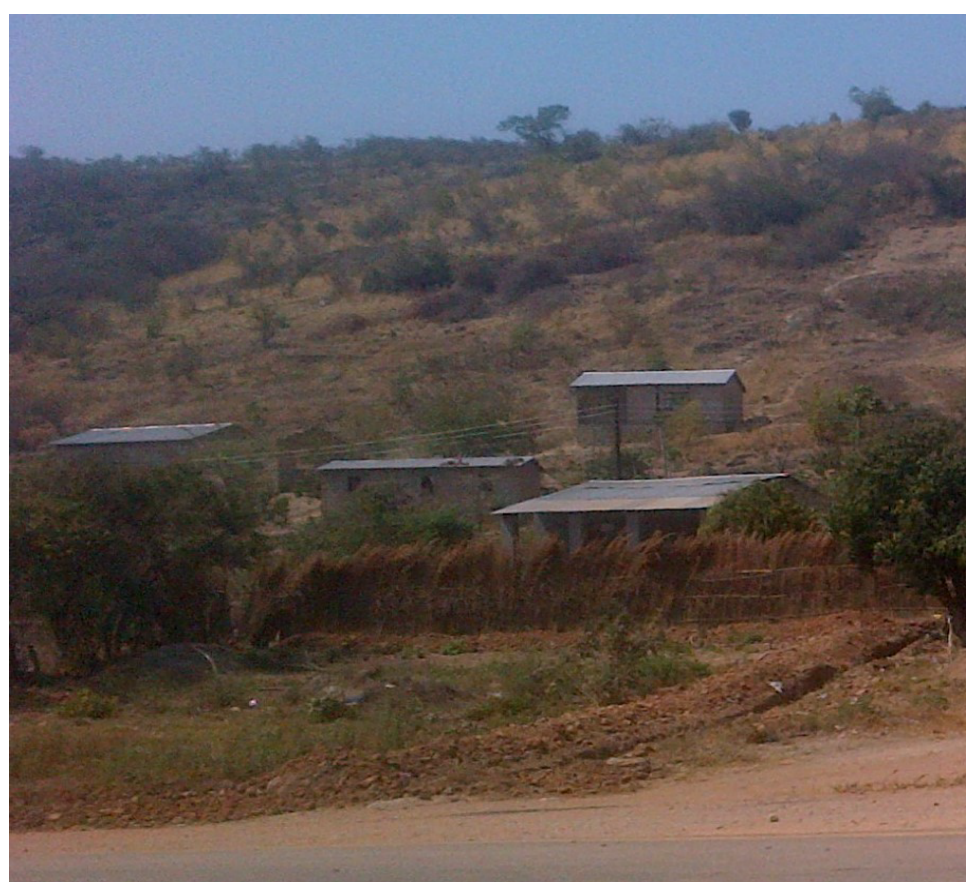

Figure 3. Typical buildings in developing countries with ungrounded metal roofs. In the event of a lightning strike to the roof it is highly possible that a side flash will leap to the body of occupants of such shelters (courtesy Mary Ann Cooper). 
ii. The quality of earth electrode plays a vital role in determining the potential rise in the vicinity. An earthing system, distributed over a large area with low ground resistance value (e.g. less than $10 \Omega$ ), is essential to maintain low potential rise in the event of a lightning strike. For example, a tower site with "bad" earthing and surge protection devices can cause significant potential elevation at the transformer which feeds the tower site and also at the earthing system of nearby utilities that receive power from the same transformer. In such cases, estimation of effective safety distance becomes extremely complicated due to multiple high potential ground points in the proximity.

iii. In the event of a lightning strike, the potential distribution and danger to humans and equipment may be significantly increased. Those who live in areas with higher soil resistivity should consider larger safety distances.

\section{Effective safe distance for avoiding secondary effects}

Human injuries due to lightning-related explosion at petrochemical installations have been reported a number of times during the last few decades. Unfortunately, it seems that the number of incidents may be increasing (explosion and fire of chemical/palm oil tanker, Bunga Alpinia, anchored at Labuan, Malaysia on 26th July 2012; fire at two naphtha tanks in El Palito oil refinery in CARACAS, Venezuela on $19^{\text {th }}$ September 2012; Fire at two storage tanks at Dow Chemical plant in New Jersey, USA on May 16, 2012; explosion and major fire at the JBS plant in Grand Island, Nebraska, USA on $14^{\text {th }}$ June 2012). In most of these cases, the actual number of victims has not been revealed. However, considering the scale of damage to the affected site, the number of injuries in each case may be significant.

Many other industries with fire and explosion risk, such as gunpowder and munitions manufacture and storage areas may pose a large safety threat to the employees and public in the neighborhood. Therefore, the lightning safety of personnel working or residing close to these installations should be assessed, taking into account the risk of secondary effects following a lightning strike. Existing guidelines address the safe distance to avoid dangerous effects due to secondary events such as fire, explosion, missiles, falling of detached masonry and tree branches, and leaking of toxic gases from damaged containers. Some of these secondary accidents may be avoided by placing partitions such as walls between places of high human activity and risk areas.

\section{Body posture}

If one is caught outdoors in a thunderstorm, the first response should be to seek safe shelter in a substantial building or all metal enclosed vehicle. If these are not available, one should keep the body posture as low as possible to decrease the chances of a direct strike or side flash from an elevated point. However, while keeping the posture as low as possible, it is also important to keep the 'footprint' of the body as small as possible to minimize step potential hazards. This lightning crouch position is well illustrated in Figure 4 and involves squatting down, keeping the feet as close together as possible and bending the head forward while closing the ears by palms (Figure 4). Although this posture is proposed in several safety guidelines, it is no longer taught in the United States due to the ready availability of safer paces to the vast majority of the population over the vast majority of the time.

It is very important that outdoor workers and sportsmen, scouts, girl guides, hikers and others be trained and made aware of this safety position. Furthermore, it is advisable to display this safety position at open recreational sites such as beaches, river banks, open stadiums, and camping sites where safe shelter, metal vehicles and other safe areas are not readily available.

Using the advanced lightning protection model that based on Monte Carlo simulation technique, proposed by Mata and Rakov [56], Roeder [25] showed that last minute action, such as taking the couching position, may reduce the risk of injury from a direct strike and also from upward leader by $56 \%$. This figure is applicable to a person on a wide flat land and it may be different when the same person is within a built up area or high grown vegetation. This study also calculated that under the same conditions, crouching on tip toes (reduced area of contact with ground) could lower the risk of step potential by $83 \%$ for the same distance between the feet.

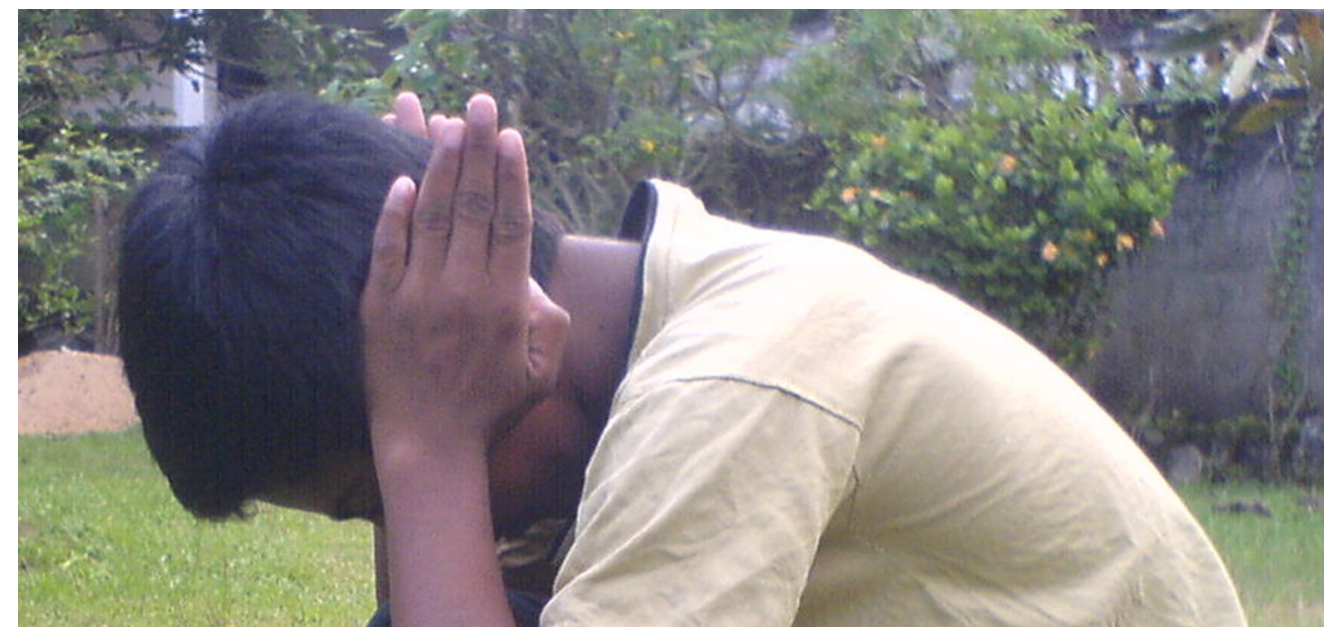

Figure 4. Lightning crouch: feet close together, low height, preferably with hands over ears. 
Although the 'lightning crouch' has been shown to decrease risk of injury by about $50 \%$ [27], it should be noted that this is the method of 'last resort' compared to rapidly seeking shelter in a safe location, building, or in an all metal enclosed vehicle. The United States Lightning Awareness Team abandoned teaching the crouch many years ago. The same researcher who found a $56 \%$ reduction in risk using the rolling spheres method has also calculated the risks of the crouch vs standing with the feet together either in an open area or a dense forest where side flash was likely. Roeder found standing to be slightly more effective than the crouch, which is difficult for many to do and certainly to maintain for any length of time [24]. Unfortunately, safer areas are often not available in agriculture, mining, homes, schools, and many other settings in developing countries [19].

\section{Contact resistance with ground or contact object}

As it was discussed earlier, a few millimeters of insulation may make a significant difference in the amount of current passing into the body of a person due to step or touch potential although the same insulation may be quite ineffective in the event of a direct strike or side flash.

Several observations on lightning step potential related animal deaths (Gomes) revealed that contact potential can play a significant role in step potential hazards. In several cases, Gomes found that four legged animals, such as deer, may suffer a lethal dose of transient current due to lightning step potential when the feet are in a few centimeters of water or a slurry of mud.

It is advisable to insulate metal railings and other metal parts of a building which are bonded to the lightning protection system but which are still accessible to the occupants. Wearing footwear made of insulating material may decrease exposure if the person is standing at a place of step potential hazard (e.g. close to a tower site).

\section{Protection of structures where safety is sought}

The level of protection given to a structure is an indication of how safe being inside such building may be. For maximum safety, a person should stay well within the outer walls of the structure. It is very rare that a person inside a sturdily built building that contains plumbing and electrical wiring will be affected by lightning, even if it is not given lightning protection, provided that there are no risks of secondary effects (fire, explosions or release of toxins) and the person of concern is not in contact with service lines such as corded telephones. In these cases, lightning strike may damage the building, but its occupants remain unaffected.

Recently, some safety promoters have begun using "sturdily built structure" to replace the older "permanent structure" term as a recommended place to seek shelter under thunderstorm conditions. Presently, disagreement exists between people in different countries on the definition of these terms. Structures that would be classified as "temporary huts" in developed countries such as the USA, Canada, and Europe, may have been the permanent residences (Figure 1) and workshops for many societal layers for many generations in developing countries in Africa, South America and parts of Asia [2,13]. The number of lightning injuries to occupants of such structures can be quite high since the risk is $24 / 7$ for all inhabitants [2,13]. It is imperative that the international community, as well as local protection people, agree to a firm definition and term for structures that are safer for people to take refuge in during thunderstorm conditions.

Note that a small structure with a suitable lightning protection scheme, a large brick or concrete building without a lightning protection system, and a metal enclosed container such as a vehicle or cargo container may be equally safe in the event of a lightning strike. We propose the term "safer structure" for a structure that provides lightning protection for its occupants. We emphasize that even though a "safe structure" may be damaged in the event of a lightning strike if it is not given a proper lightning protection scheme, it may still protect occupants. Although Gomes et al. [20] proposed low cost lightning protection systems for small structures (both stationery and movable) and Gomes and Kadir [21] proposed the ways of reducing the cost of lightning protection scheme for structures with steel reinforcement, these have yet to be tested for lightning safety.

\section{Protection of service wires entering a structure}

Unless suitably rated surge protective devices (SPDs) are connected at line entrances to buildings, service lines such as power, communication, data and cable TV may deliver lightning surges (voltage or current) harmful to the people using or close to the lines (e.g. using hard wired phones, repairing electrical lines, or operating powered equipment). It is important to note that unless a properly coordinated network of SPDs is installed with a proper grounding system, equipment may be damaged even if the occupants are unharmed [3]. People should avoid the use of any hard wired equipment during a thunderstorm since they may not know the level of protection a building provides.

An additional risk may arise due to ignition of building materials such as thatch, polythene, or dry wood by direct strikes, side flashes or arcing due to surge from incoming wire. Buildings, especially those situated in high lightning risk locations, should have suitable coordinated surge protection which meets recognized standards and guidelines [3].

\section{Society and neighborhood}

No one and no standard can guarantee absolute safety from lightning injury to either people or equipment, but relying on accepted standards for structural and surge protection against lightning provides the greatest degree of safety indoors. In high to medium income societies, awareness programs will be able to prompt the public to adopt proper lightning protection measures for themselves and their properties. Indoor lightning accidents in the U.S. have become extremely rare during the last few decades (Interview by Rebecca J Rosen of The Atlantic with lightning expert Ron Holle on 14-01-2014). However, many lightning accidents have occurred outdoors to people within meters of safer structures. Proper lightning protection of structures and equipment has no impact if people are not willing to seek safety.

Unfortunately, secondary effects of lightning strikes to neighboring structures or facilities may injure bystanders within their own property due to explosions, fire, missiles, 
step potential, falling materials, and other mishaps. Hence, even if one has proper protection for his property, the lack of protection in the neighborhood, which is beyond his control, may cause adverse effects to him. An example occurred in June, 2013, when lightning hit a tall building in Penang, Malaysia, and caused mechanical failure of the building's metal structure which collapsed into an adjoining building, killing one person and damaging seven vehicles. In Southern and Eastern Africa, there have been several cases where a lightning caused fire to a house in a densely populated community and spread to other structures in the area. In such cases, a single lightning protected house in the community cannot be expected to remain unharmed since a lightning protection system (LPS) does not provide protection from fire or explosion.

On the other hand, in most parts of the world, low income societies may not be able to afford proper LPS due to the high cost of such systems relative to their income [2]. In such circumstances, there should be guidelines to give the maximum personal safety within the frame of available facilities, as the risk management strategies applicable in developed societies [61] may totally or partially fail due to lack of awareness and facilities. Low-cost LPS may be required in such societies. Proper public education on lightning safety should be given to everyone [28].

As discussed in Mary and Gomes [2] and Gomes and Gomes [4], many communities with lower levels of education, especially those in developing countries, may ignore safety guidelines unless there is a hierarchical order of hazard control and a ladder of responsibility distribution. The hazard control mechanism should include awareness, forecasting, technology, local control and substitution, whereas the responsibility mechanism should ladder down in the sequence: government, non-governmental organizations, local authorities, community leadership and potential victim Community myths and beliefs should be taken into account in developing the safety model for any community.

\section{Conclusions}

This paper shows that lightning may affect human beings and animals by several primary and secondary mechanisms. The complex nature of each injury mechanism has been discussed in detail. While it will be impossible to prevent all lightning injuries (the 'bolt from the blue' first strike without prior warning) most injuries from lightning can be prevented. There are various parameters that influence the risk of lightning accidents, apart from the ground flash density. These include: body posture, topography, conductivity of the lightning struck object, soil resistivity, nature of the structure and shelter, and isolation. Although the complex interaction of injury mechanisms and accident environment makes the development of a set of optimized safety guidelines against all types of possible lightning effects seem like a daunting task, the development of guidelines on human safety, cross-referenced with existing lightning protection standards, is essential. The primary objective of this work is to prepare the foundation for such a set of guidelines.

Whereas some safety guidelines are globally applicable, others, in developed countries may not be applicable in many developing countries due to socio-economic factors and affordability. Those responsible for developing safety guidelines should take many factors into account in addressing a certain region or community including the literacy rate, income modality, religious and cultural practices, nature of available shelter and other factors that may be important.

\section{References}

1. Holle RL, López RE, Zimmermann C. Updated recommendations for lightning safety-1998: Bulletin of the American Meteorological Society. 1999;80:2035-41.

2. Mary AK, Gomes C. Lightning accidents in Uganda. 31st International Conference on Lightning Protection (ICLP2012) Vienna, Austria. 2012.

3. Gomes C. On the selection and installation of surge protection devices in a TT wiring system for equipment and human safety, Safety Science. 2011;49:861-70.

4. Gomes A, Gomes C. Hierarchy of Hazard Control to Minimize Lightning Risk, 32nd International Conference on Lightning Protection-2014, Shanghai, China, October. $2014 ; 1218-28$

5. Gao Yi, Zhang Y, Zhang W, et al. Characteristics of lightning casualties and vulnerability evaluation regionalization in China. Journal of Applied Meteorological Science. 2012;23(3):294-303.

6. Cardoso I, O Pinto Jr, Pinto IRCA, et al. A new approach to estimate the annual number of global lightning fatalities. 14th International Conference on Atmospheric Electricity, August 8-12, Rio de Janeiro, Brazil. 2011; 4 p.

7. Cruz C, Rentería C, Roman FJ. Statistics of the Colombian National Army lightning accidents. Preprints, Intl. Symp. Lightning Protection (XII SIPDA), Belo Horizonte, Brazil. 2013;6 p.

8. Navarrete-Aldana N, Cooper MA, Holle RL. Lightning fatalities in Colombia from 2000 to 2009. Natural Hazards. 2014;74:1349-62.

9. Holle RL. Some aspects of global lightning impacts. Preprints, 7th Conference on the Meteorological Applications of Lightning Data, January 4-8, American Meteorological Society, Phoenix, Arizona. 2015;8 p.

10. Trengove E. Lightning myths and beliefs in South Africa: Their effect on personal safety, PhD Thesis, University of the Witwatersrand, Johannesburg, South Africa. 2013.

11. Blumenthal R, Jandrell IR, West NJ. Does a sixth mechanism exist to explain lightning injuries? Investigating a possible new injury mechanism to determine the cause of injuries related to close lightning flashes. American Journal of Forensic Medicine and Pathology. 2012;33:222-26.

12. Blumenthal R. Secondary missile injury from lightning strike. Am J Forensic Med Pathol. 2012;33:83-5.

13. Lubasi FC, Ab Kadir MZA, Gomes C, et al. Case studies of lightning related injuries and property damage in Zambia, 31st International Conference on Lightning Protection (ICLP-2012) Vienna, Austria. 2012. 
14. Blumenthal $\mathrm{R}$. The forensic investigation of fatal lightning strike victims: Reconsidered and revised. Preprints, International Conference on Lightning Protection, September 2-7, Vienna: Austria. 2012; 5 p.

15. Cooper MA, Holle RL. Lightning Safety Campaigns- USA Experience, 32nd International Conference on Lightning Protection, Vienna. 2012.

16. Cooper MA. Whether the Medical Aspects of Lightning Injury Are Different in Developing Countries, 32nd International Conference on Lightning Protection, Vienna, 978-1-4673-1897-6/12/\$31.00 C2012 IEEE. 2012.

17. López RE, Holle RL, Heitkamp TA, et al. The underreporting of lightning injuries and deaths in Colorado. Bulletin of the American Meteorological Society. 1993;74:2171-78.

18. Holle RL. Annual rates of lightning fatalities by country. Preprints, Intl. Lightning Detection Conf., Tucson, Ariz., Vaisala. 2008;14 p.

19. Holle RL, Jensenius J, Roeder WP, et al. Comments on lightning safety advice on running to avoid being struck. International Conference on Lightning and Static Electricity, August 28-31, Paris, France, paper IC07/ PPRKM03. 2007;6 p.

20. Gomes C, Ab Kadir MZA, Cooper MA. Lightning Safety Scheme for Sheltering Structures in Low-Income Societies and Problematic Environments, 31st International Conference on Lightning Protection-2012, Vienna, Austria, September. 2012.

21. Gomes C, Ab Kadir MZA, Efficient lightning protection: Optimization of economic, environmental and safety aspects, Environmental Engineering and Management Journal. 2015;14(8):1975-85.

22. Gomes C, Ahmed M, Žele D. Lightning and Fish Mortality: Case Study from Bangladesh, 31st International Conference on Lightning Protection-2012, Vienna, Austria, September. 2012.

23. Gomes C. Lightning safety of animals, International Journal of Biometeorology. 2012;56:1011-23.

24. Roeder WP. Backcountry lightning risk reduction lightning crouch versus standing with feet together, $5^{\text {th }}$ International Lightning Meteorology Conference, Tucson, Arizona, USA, May. 2014.

25. Roeder WP, Cummins BH, Ashley WS, et al. Mapping Lightning Fatality Risk, 5th International Lightning Meteorology Conference, Tucson, Arizona, USA, May. 2014.

26. López RE, Holle RL. The distance between successive lightning flashes, NOAA technical memorandum, ERL, NSSL-105, Norman OK, National Severe Storms Laboratory. 1999;29.

27. Roeder WP. The Effectiveness of Short Notice Outdoor Lightning Risk Reduction and Why It Should Not Be Taught, International Conference on Lightning and Static Electricity, August 28-31, Paris, France. 2007;7 p.
28. Roeder WP, Holle RL, Cooper MA, et al. Lessons Learned In Communicating Lightning Safety Effectively, 4th International Lightning Meteorology Conference, Broomfield, Colorado, USA. 2012.

29. Uman MA. All About Lightning. Dover Publications, New York. 1986.

30. Cooper MA. Myths, miracles, and mirages, Seminars in Neurology. 1995;15(4):358-61.

31. Kitagawa NM, Ohashi, Ishikawa T. Safety guide against lightning hazards. Research Letters in Atmospheric Electricity. 1990;10:37-44.

32. h t t p : / / n e w s. nation a lgeographic . com/ news/2004/06/0623_040623_lightningfacts.html

33. Andrews CJ, Berger G, Floret N, et al. International safety and rescue guide against lightning hazards. Proceedings, 23rd International Conference on Lightning Protection, September 23-27, Florence: Italy. 1996;738-43.

34. Andrews CJ, Berger G, Floret N, et al. International safety and rescue guide against lightning hazards. Proceedings, Lightning and Mountains '97, June 1-5, Chamonix MontBlanc, France, 211. 1997.

35. Bennett BL. A model lightning safety policy for athletics. Journal of Athletic Training. 1997;32:251-53.

36. Bennett BL, Holle RL, López RE. Lightning safety. 199798 NCAA Sports Medicine Handbook, Ninth Edition, M. Benson, Editor, National Collegiate Athletic Association, Overland Park, KS, 12-14. 1997.

37. Zimmermann C, Coopermand MA, Holle RL. Lightning safety guidelines. Annals of Emergency Medicine. 2002;39:660-65.

38. Walsh KM, Cooper MA, Holle RL, et al. National Athletic Trainers' Association Position Statement: Lightning Safety for Athletics and Recreation. Journal of Athletic Training. 2013;48:258-70.

39. American Meteorological Society. Lightning safety awareness [AMS statement and background from AMS Council], Bulletin of the American Meteorological Society. 2003;84:260-61.

40. Cooper MA. Lightning Injuries: Prognostic Signs for Death. Ann Emerg Med. 1980;9(3):134-38.

41. Cooper MA, Andrews CJ, Holle RL, et al. Lightning injuries. Wilderness Medicine. 7th ed. Auerbach P, editor. Elsevier Mosby: Philadelphia; 2016;60-101.

42. Cooper MA. A fifth mechanism of lightning injury. Acad Emerg Medicine. 2002;9:172-74.

43. Cooper MA, Holle RL, Andrews CJ. Distribution of lightning injury mechanisms, 2nd International Lightning Meteorology Conference, Tucson, Arizona, USA. 2008.

44. Arora R, Gomes C. Need for Awareness, Detection and Protection from Damage Caused by Lightning, NAM S\&T Centre, India, ISBN 978-81-7035-579-3. 2008. 
45. Sharma S. Natural Disasters; Policy Issues and Mitigation Strategies, NAM S\&T Centre, India, ISBN 978-81-7035759-9, 2011. 2012.

46. Andrews CJ, Darveniza M. Telephone mediated lightning injury: An Australian survey. J Trauma. 1989;29:665.

47. Fisher RJ, Schnetzer GH, Thottappillil R, et al. Parameters of triggered-lightning flashes in Florida and Alabama, Journal of Geophysics Research. 1993;98:22887-902.

48. Fisher RJ, Schnetzer GH. Triggered Lightning Test Program: Environments within 20 meters of the lightning channel and small area temporary lightning protection concepts, Sandia National Laboratories Report SAND930311, Albuquerque, NM. 1994.

49. Zhang Y, Zhang W, Meng Q. Lightning Casualties and Damages in China from 1997 to 2010, 31st International Conference on Lightning Protection (ICLP-2012) Vienna, Austria, Article number 978-1-4673-1897-6/12. 2012.

50. Pinto IRCA, Cardoso I, Pinto O Jr, et al. Lightning fatalities in Brazil in the last decade. Preprints, Intl. Lightning Meteorology Conf., Orlando, Fla., Vaisala. 2010;3 p.

51. Blumenthal R. Lightning fatalities on the South African Highveld: A retrospective descriptive study for the period 1997-2000. Amer J Forensic Med Pathology. 2005;26:66-9.

52. Blumenthal R, West NJ. Investigating the risk of lightning's pressure blast wave, South African Journal of Science. 2015;111:1-5.

53. Cardoso I, O Pinto Jr, Pinto IRCA, et al. Lightning casualty demographics in Brazil and its implications to safety rules. Preprints, 14th Intl. Conf. Atmospheric Electricity, Rio de Janeiro, Brazil. 2011:4 p.
54. Chandimal APL, Gomes C. Lightning Related Effects to the Neighborhood Due to the Presence of Telecommunication Towers, 31st International Conference on Lightning Protection-2012, Vienna, Austria, September. 2012.

55. Gookin J. NOLS backcountry lightning safety guidelines. Preprints, International Lightning Detection Conference, October 16-18, Tucson, Arizona, Vaisala, Tucson, 8. 2002.

56. Mata CT, Rakov VA. Evaluation of lightning incidence to elements of a complex structure: A Monte Carlo approach, International Conference on Grounding and Earthing and 3rd International Conference on Lightning Physics and Effects, Florianopolis, Brazil. 2008.

57. Vavrek J, Holle RL, Allsopp J. Flash to Bang. The Earth Scientist, National Earth Science Teachers Association. 1993;10:3-8.

58. Ghasem N, Mahdi Izadi, Gomes C, et al. Variation of minimum safety separation for non-conducting lightning targets, International Conference on Lightning Protection (ICLP), Shanghai, China. 2014.

59. Schnetzer GH, Fisher RJ, Rambo KJ. 1996 Joint Sandia/ University of Florida Triggered Lightning Test Program: Temporary Lightning Protection System experiments and direct-strikes to explosive materials, Department of Electrical and Computer Engineering, University of Florida, Gainesville: FL, 1996:15-19.

60. Nag A, Murphy MJ, Schulz W, et al. Lightning locating systems: Insights on characteristics and validation techniques. Earth and Space Science. 2015;2:65-93.

61. Gookin J. Backcountry Lightning Risk Management, 3rd International Lightning Meteorology Conference, Orlando, Florida, USA, April. 2010.

\section{*Correspondence to:}

Chandima Gomes

Centre for Electromagnetic and Lightning Protection

Research

University Putra

Malaysia

E-mail: chandima.gomes@gmail.com 